\title{
Quantifying and Predicting Reactive Transport of Uranium in Waste Plumes: Are Colloids and Nanoparticles Important?
}

\author{
(Project 90171)
}

\author{
Lead-Investigator: Jiamin Wan ${ }^{\#}$ (jmwan@lbl.gov) \\ Co-investigators: $\quad$ Tetsu Tokunaga ${ }^{\#}$, Carl Steefel $^{\#}$, and Peter Burns ${ }^{*}$ \\ ${ }^{\#}$ Lawrence Berkeley National Laboratory \\ * University of Notre Dame
}

\section{Research Objectives}

The Hanford Site is the DOE's largest legacy waste site, with uranium (U) from plutonium processing being a major contaminant in its subsurface. Accidental release of highly concentrated high-level wastes left large quantities of $U$ in the vadose zone under tank farms. The $\mathrm{U}$ contamination has been found in groundwater beneath the tank farms, indicating $\mathrm{U}$ is mobile. Because excavation costs are enormous, this $\mathrm{U}$ will likely be left in-ground for the foreseeable future. Therefore, understanding the contamination processes and the resulting $\mathrm{U}$ spatial and temporary distributions and mobility in the heavily contaminated Hanford site is needed in order to forecast its future transport. The overall objective of this research is to develop an experimentally supported conceptual model of $\mathrm{U}$ reactive transport, during and after the tank leakage, at heavily Ucontaminated areas of the Hanford vadose zone. The conceptual model will incorporate key geochemical and physical controls on the contamination process, explain the current distribution of $\mathrm{U}$ in the vadose zone, and guide predictions of its future mobility under the influence of natural recharge. We do not seek to predict the complex flow geometry of any specific waste plume. Instead, our work is trying to identify the hierarchy of processes relevant along $\mathrm{U}$ waste plume paths.

\section{Research Progress and Implications}

This report summarizes progress of the project during the past three years (20042006). In pursuit of our research objective, we chose to simulate the tank BX-102 /overfill event (the largest single spilling event of $U$ release in the country, left 8 tons of $U$ in the vadose zone). We synthesized the Metal Waste Solution (MWS) based on the historical recipe. The MWS contained $0.11 \mathrm{M} \mathrm{U}(\mathrm{VI}), 3.6 \mathrm{M}$ sodium, $0.6 \mathrm{M}$ carbonate, and had a $\mathrm{pH}$ of 10.4. The tank waste spilling event was simulated using the column plume profiling method we developed earlier (Figure 1). The synthesized MWS was injected into columns of different lengths, at $70^{\circ} \mathrm{C}$, and at varied flow rates. Flow was stopped just before the plume front reached the opposite end of the column. Then the column was sectioned and the pore liquid was extracted from each segment of the column. Temporally and spatially resolved chemical and physical properties of plume pore liquids and sediments were determined to obtain profiles of geochemical characteristics of the plumes. The main findings are summarized here.

1. Massive quantities of U-containing colloids formed within plume front pore liquids. The extracted plume liquid at plume front location contained massive quantities of colloids, including U containing colloids (Figure 2, 3). 
2. Dramatic $\mathrm{pH}$ decrease found in plume front pore liquids. The $\mathrm{pH}$ decreased to as low as 6.4 at the front; 4 units lower than the $\mathrm{pH}$ of initial waste solution $(\mathrm{pH} 10.4)$, and two units lower than the $\mathrm{pH}$ of the displaced native sediment water $(\mathrm{pH} 8.4)$. The $\mathrm{pH}$ reduction at the plume front is largely responsible for colloid formation at the plume front location.

3. Large $\mathrm{Ca}^{2+}$ and $\mathrm{Mg}^{2+}$ enrichment found within plume front pore liquids. Sharp $\mathrm{Ca}^{2+}$ and $\mathrm{Mg}^{2+}$ peaks were found at the plume front liquids. As a consequence, precipitation of these supersaturated divalent cations as carbonates resulted in $\mathrm{pH}$ reduction at the plume front.

4. Fast $\mathrm{U}$ transport found within plumes. Fast $\mathrm{U}$ transport in the plume liquid phase was observed, with very high concentrations of $U$ accumulated at the plume front. Uranium peak concentrations reached as high as 5.8 times of the initial $\mathrm{U}$ concentration in the injected waste solution. The fast transport of $U$ most likely resulted from the formation and preferential (size exclusion) transport of U-colloids.

5. Flow rate is an important control on overall $U$ behavior in the waste plumes. The extent of all aforementioned phenomena increase with increased flow rate. The degree of $\mathrm{U}$ retardation by sediments increased with reduced flow rate, showing that kinetics of sorption and precipitation controlled retardation.

6. The geochemical properties of laboratory plume profiles can be scaled up to be fieldrelevant when applied along appropriate flow paths (generally not 1-dimensionally). The aforementioned conclusions (1 through 5) are now well tested for plume lengths from 0.2 to 2.0 meters.

Reactive transport modeling for matching the time-dependent liquid saturation and nonreactive tracer fronts in the column experiments is in progress. Modeling of the solution $\mathrm{pH}$ was carried out by including various mineral precipitation and dissolution reactions, the most important of which is calcite. Calcite precipitated because of the high bicarbonate in the injection solution and because of the desorption of $\mathrm{Ca}^{+2}$ from cation exchange sites on the clays as a result of the elution of the high $\mathrm{Na}^{+}$, which competes for exchange sites with the $\mathrm{Ca}^{+2}$. The precipitation of calcite releases hydrogen ion, thus lowering the $\mathrm{pH}$. The simulations predict the precipitation of minor amounts of sodium uranium carbonate, a phase identified by XRD in the columns, but only upstream of the calcite front, since the precipitation of calcite decreases bicarbonate in solution and destabilizes the sodium uranium carbonate. The modeling results will be soon summarized in a manuscript.

Although U geochemistry has been extensively studied, the processes of U-colloid precipitation and fast $\mathrm{U}$ transport within the plumes have not been previously revealed, and was not predictable using transport models that assume local equilibrium $\left(\mathrm{K}_{\mathrm{d}}\right)$. This may explain the efficient $U$ transport and highly variable retardation observed within the alkaline waste plumes in the field. 


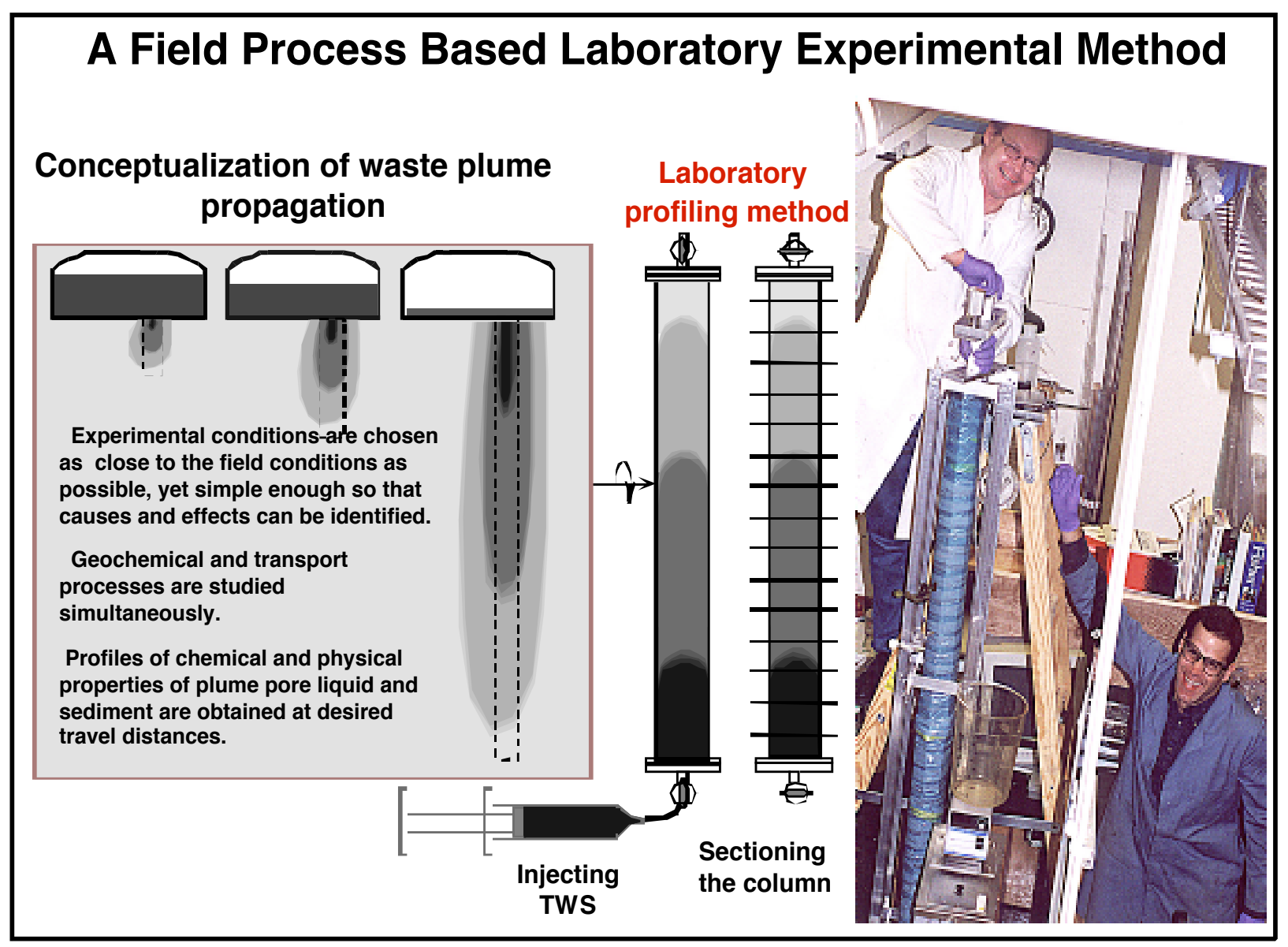

Figure 1. Laboratory column plume profiling method.

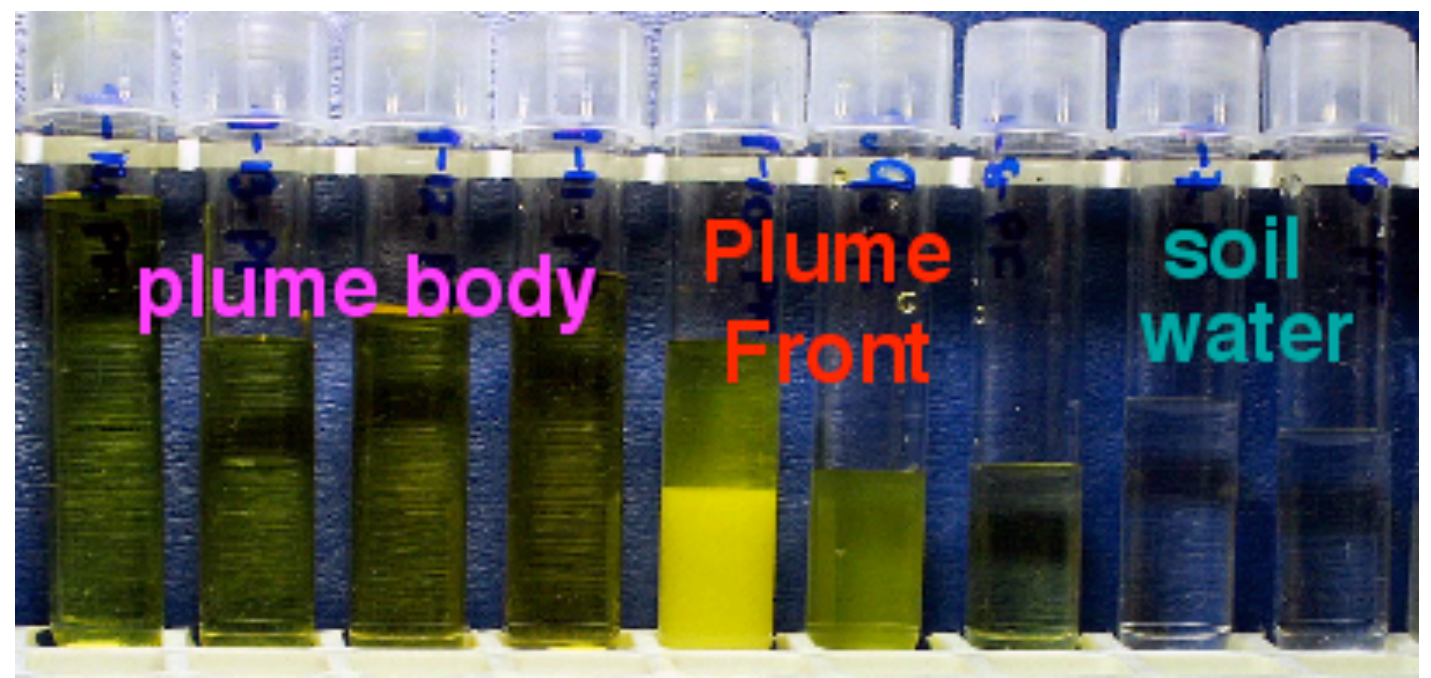

Figure 2. Photograph of a profile of extracted pore solutions from a simulated $U$ plume at the time of initial plume formation. The flow direction is towards the right. Large quantities of $\mathrm{U}$ colloids formed at the plume front. 


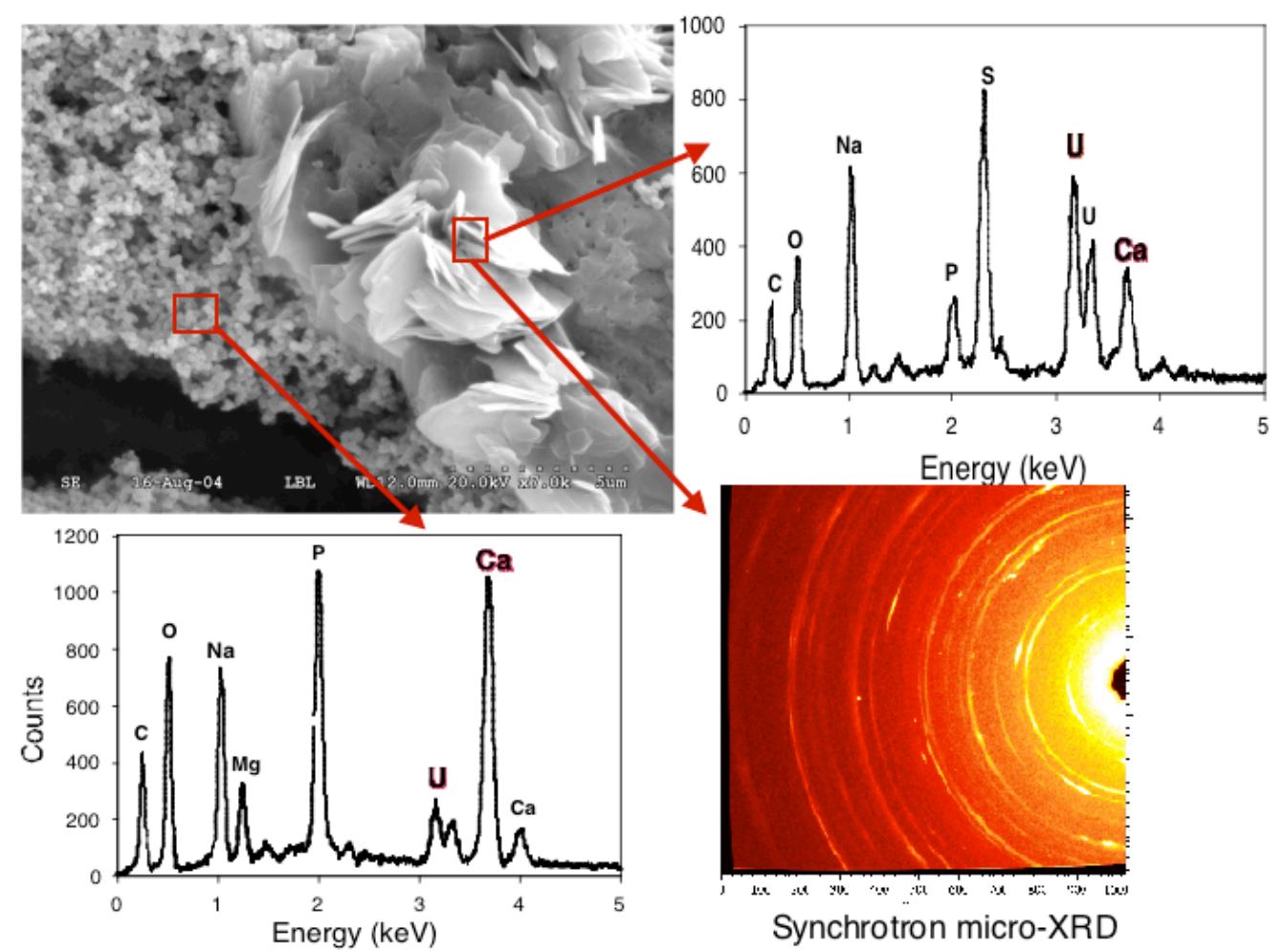

Figure 3. Characterization of the plume front colloids: morphology, chemical composition, and structure. The well crystallized colloidal phase was identified as Cejkaite $\left[\mathrm{Na}_{4}\left(\mathrm{UO}_{2}\right)\left(\mathrm{CO}_{3}\right)_{3}\right]$

\section{Project Publications}

Wan, J., T. K. Tokunaga, E. Saiz, J. T. Larsen, Z. Zheng, and R.A. Couture, Colloid formation at waste plume fronts, Environ. Sci. Technol. 38, 6066-6073, 2004.

Wan, J., J.T. Larsen, T.K. Tokunaga, Z. Zheng, pH neutralization and zonation in alkaline-saline tank waste plumes. Environ. Sci. Technol. 38, 1321-1329, 2004.

Wan, J., T. K. Tokunaga, J.T. Larsen, and R. J. Serne, Geochemical evolution of highly alkaline and saline tank waste plumes during seepage through vadose zone sediments. Geochim. Cosmochim. Acta. 68, 491-502, 2004.

Zheng, Z. and J. Wan, Release of contaminant U(VI) from sediments, Radiochim. Acta, 93, 1-7, 2005.

Zhang, G., Z. Zheng, J. Wan, Modeling reactive geochemical transport of concentrated aqueous solutions in variably saturated media. Water Resour. Res., 41, W02018, doi: 10.1029/2004 WR003097, 2005.

Wan, J. and T.K. Tokunaga, Comments on "Pore-Scale Visulization of Colloid Transport and Retention in Partly Saturated Porous Media”, Vadose Zone J., 4, 954-956, 2005.

Zheng, Z., J. Wan, X. Song, and T.K. Tokunaga. Sodium meta-autunite colloids: Synthesis, characterization, and stability. Colloids Surfaces A. Physicochemical Eng. Aspects, 274, 48-55, 2006. 
Wan, J., T. K. Tokunaga, Y. Kim, Z. Wang, J. R. Serne, and A. Lanzirotti, Reactive Transport Behavior of U(VI) upon the Largest Unplanned Release into the Hanford Vadose Zone, to be submitted to Environ. Sci. Technol, 2006.

Wan, J., Y. Kim, T. K. Tokunaga, Z. Wang, and Y. T. He, Effects of Ageing on Uranium Fate and Transport within the Waste Plume in the Hanford Vadose Zone, in preparation.

\section{Acknowledgments}

We thank Jeffrey Serne (PNNL) for providing the U Metal Waste solution recipe and helpful discussion on its synthesis, Zheming Wang (EMSL) for analyzing aqueous U species in pore solutions using time-resolved laser fluorescence spectroscopy, Tony Lanzirotti (University of Chicago) for conduction the synchrotron micro-XRD analyses of U-containing colloid phase (beamline X26A, NSLS), and Joern Larsen, Yongman Kim, and Tom He (LBNL) for column experiment operation and analyses. 